\title{
On the Relationships among EFL Learners' Willingness to Communicate, Communication Apprehension, Self-Perceived Competence and Emotional Intelligence
}

\author{
Saeed Mehrpoor \\ Shiraz University, Iran \\ Neda Soleimani \\ Shiraz University, Iran
}

\section{Introduction}

Language learning is largely concerned with communication and apart from the skills and abilities that are required to enable a learner to establish communication, learners' desire or willingness to communicate also plays a crucial role in the development of their communicative skills. Willingness to communicate (WTC) is commonly defined as learners' tendency to initiate a conversation when given the choice and voluntarily engagement in a communication (McCroskey, 1992; McCroskey \& Baer, 1985).

WTC came into limelight by McCroskey and his colleagues (1991) in reference to individual differences in first language (L1) communication. Later on MacIntyre and Charos (1996) introduced the idea of WTC in second language acquisition in such a way that developing L2 learners' WTC is now considered as the ultimate goal of any modern second language (L2) program (MacIntyre, Clément, Dörnyei \& Noels, 1998). With the advent of communicative approaches to L2 teaching and learning such as communicative language teaching (CLT), enhancing L2 learners WTC has been highlighted as one of the major goals in L2 teaching programs (MacIntyre, 2003). A repertoire of diverse variables are purported to underpin individuals` WTC and other personal, biological, contextual, and psychological communication-related factors (Beatty, McCroskey, \& Heisel, 1998; Donovan \& MacIntyre, 2004). 
WTC is tightly interwoven with other communication-related variables including Communication Apprehension (CA) and Self-Perceived Communication Competence (SPCC) (McIntyre, 2003). CA is defined as "individuals' fear or anxiety to start a communication with another person or persons" (McCroskey, 1997). SPCC refers to perceptions of individuals in a communicational situation. If an individual perceives himself as competent for communication in a situation, he tends to be less apprehensive and more willing to initiate a conversation (MacIntyre, 1994; McCroskey \& Richmond, 1991).

Though a growing body of theoretical and empirical queries has, to date, examined factors contributing to learners` L2 WTC and its underlying variables, the role of social psychological factors in this process deserves further research. One such factor is emotional intelligence (EI). Past research in mainstream social psychology has documented the positive role of EI in coping with environmental demands and pressures (Bar-on, 1997, 2002). L2 acquisition research has instantiated the facilitative role of EI as both an internal and an external mechanism in L2 learning (Brown, 2000; Goleman, 2001). Given that learners`L2 WTC is seen to be a function of their ability to adapt to a new learning situation, it seems that it is amenable to EI. In fact, the purpose of the present study was to investigate possible links between learners` willingness to initiate a conversation in an L2 and their EI. Gardner (1983) was one of the pioneer scholars whose multiple intelligence theory unfolded multidimensionality of intelligence. Form this theory the notion of intelligences was introduced and he concepts of interpersonal and intrapersonal intelligences paved the way for a more comprehensive understanding of EI or EQ. EI is not a clearly defined term; however, Goleman (1995:34) proposed one of the most commonly referred definitions as follows: "abilities such as being able to motivate oneself and persist in the face of frustration, to control impulses and delay gratification; to regulate one's moods and keep distress from swapping the ability to think; to emphasize and to hope". The positive role of emotional intelligence in coping with environmental demands and pressures has been highlighted in studies by Bar-on (1997, 2002). EI plays a facilitative role as both an internal and external mechanism in L2 or foreign language learning (Goleman, 2001), and as mentioned earlier, learners' WTC could be affected by psychological variables. However, few studies have focused on the possible connection between EFL learners' WTC, SPCC, CA and EI in EFL contexts (Brackett \& Katulak, 2007).

Although the construct of L2 WTC has been investigated in considerable empirical studies, there are still many questions to be answered. With L2 acquisition relying heavily on using L2 for the purpose of communication and the increasing emphasis of modern language pedagogy on the role of communication in L2 acquisition, one question to be explored is how L2 WTC affects linguistic and non-linguistic aspects of L2 learning. Following that, the present study aims to explore the effect of L2 WTC on learners preferences for different aspects of L2 learning and instruction. 


\section{Theoretical Background}

\subsection{Emotional Intelligence (EI)}

Bar-On (1997: 14) coined emotional intelligence (EI) and defined it, "an array of non-cognitive capabilities, competencies, and skills that influence one's ability to succeed in coping with environmental demands and pressures". In 2006, Bar-On developed his model in which EI is categorized into five broad subcomponents: intrapersonal, interpersonal, adaptability, stress management, and general mood. It is worth noting to note that the theoretical background of the current study is based on Bar-On's model (2006) (see table 1).

Table 1. The EQ-i Scales and What They Measure

\begin{tabular}{ll}
\hline The EQ-I Scales & The EI Competencies and Skills Assessed by Each Scale \\
\hline Intrapersonal & Self-awareness and self-expression: \\
\hline Self-Regard & To accurately perceive, understand and accept oneself. \\
\hline Emotional Self-Awareness & To be aware of and understand one's emotions \\
\hline Assertiveness & $\begin{array}{l}\text { To effectively and constructively express one's emotions } \\
\text { and oneself. }\end{array}$ \\
\hline Independence & $\begin{array}{l}\text { To be self-reliant and free of emotional dependency on } \\
\text { others }\end{array}$ \\
\hline Self-Actualization & $\begin{array}{l}\text { To strive to achieve personal goals and actualize one's } \\
\text { potential. }\end{array}$ \\
\hline Interpersonal & Social awareness and interpersonal relationship: \\
\hline Empathy & To be aware of and understand how others feel \\
\hline Social Responsibility & $\begin{array}{l}\text { To identify with one's social group and cooperate with } \\
\text { others }\end{array}$ \\
\hline Interpersonal Relationship & $\begin{array}{l}\text { To establish mutually satisfying relationships and relate well } \\
\text { with others. }\end{array}$ \\
\hline Stress Management & Emotional management and regulation: \\
\hline Stress Tolerance & To effectively and constructively manage emotions. \\
\hline Impulse Control & To effectively and constructively control emotions \\
\hline Adaptability & Change management \\
\hline Reality -Testing & $\begin{array}{l}\text { To objectively validate one's feelings and thinking with } \\
\text { external reality. }\end{array}$ \\
\hline Flexibility & $\begin{array}{l}\text { To adapt and adjust one's feelings and thinking to new } \\
\text { situations. }\end{array}$ \\
\hline Problem-Solving & $\begin{array}{l}\text { To effectively solve problems of a personal and } \\
\text { interpersonal nature }\end{array}$ \\
\hline General Mood & Self-motivation \\
\hline Happimism & To be positive and look at the brighter side of life. \\
\hline & To feel content with oneself, others and life in general \\
\hline
\end{tabular}

\subsection{Willingness to communicate (WTC) and Communication Traits}

In the present study, the researchers adopted WTC model proposed by Macintyre, Clément, Dörnyei and Noels (1998). In this theoretical model, underlying cognitive context, motivational factors, individual contexts and behavioral issues affecting WTC in L2 are depicted (see figure 1). Of the most related variables to WTC, 
communication apprehension (CA) and self-perceived competence (SPCC) are of the interest in this study.

Figure1. Heuristic model of variables influencing WTC (Macintyre, Clément, Dörnyei, \& Noels, 1998, p. 547)

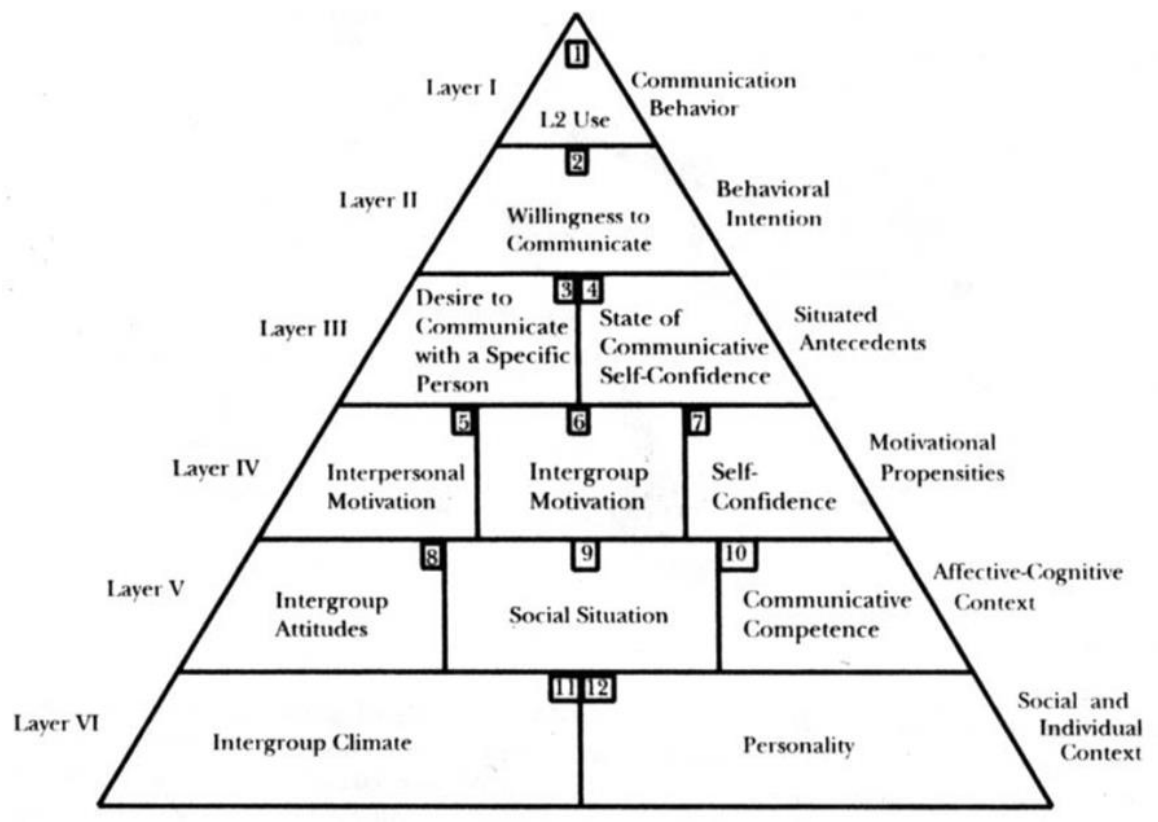

\section{Review of Related studies}

\subsection{Relevant Studies on EI}

Although the role of EI in education has been the focus of several studies in different fields, few studies have focused on the role of EI in conjunction with other variables in ESL/EFL contexts. In Nigeria, Salami (2007) studied the connection between EI to the secondary school teachers' attitude about work. Results of his study showed that EI significantly affected teachers' work attitudes. In another study in India, Lenka and Kant (2012) asserted that EI and professional development were related to each other.

In Iran, Aghasafari (2006) examined the relationship between emotional intelligence and second language learning strategies among 100 Azad University students and the results indicated a strong relationship between EI and language learning strategies. In a similar study, Pishghadam (2007) determined the relationship between 528 Iranian university students' EI and their language achievement in Tehran. Based on this study, significant relationships were found 
among intelligence scores and Grade Point Average (GPA), and students' scores on four language skills. Fahim and Pishghadam (2007) conducted a study on the relationship between EQ, IQ and verbal intelligence with the academic achievement of Iranian students majoring in English language. The results showed a positive correlation among students' academic success and dimensions of EI including intrapersonal, stress management and general mood competencies. Moreover, IQ was not found to affect academic achievements.

In an experimental study, Pishghadam (2009) studied the effect of emotional and verbal intelligences on efficacy and success of English language learning in Iran. To draw a more precise snapshot of learning, he collected and analyzed both the product and the process data. Findings of his study in product-based phase reflected the significant role of EI in learning productive skills. In the processbased phase, the results indicated the impact of EI and verbal intelligence on the number of errors, turn-taking, amount of communication.

In another study, Azimitabar, Gorjian and Pazhakh (2012) examined the impact of EI on production and recognition of test item formats in reading comprehension. They studied the impact of Emotional Intelligence (EI) on male and female high school students. Results of Two-way ANOVA revealed that a significant difference existed between males and females in using EI faculties on test taking processes.

In an investigation on the relationship between EI and language achievement, Rokhi, Hamidi and Gorgani (2014) studied a sample of non-TEFL students using Bar-On's (1997) inventory to collect data. That study revlead a significant relationship between EI and language success. Moreover, the effect of gender on EI was found to be significant.

\subsection{Studies into WTC and Communication traits}

The delineation of WTC and other communicative constructs motivated several studies. McCroskey (1992) extensively scrutinized the relationship between WTC and communication traits and he found a positive connection between SPCC and WTC and a negative association between WTC and CA. Following some general studies into WTC, a new wave of studies were implemented into the impact of various variables on WTC and communication traits.

For instance, Baker and MacIntyre (2000) studied the association between gender and immersion L2 programs. The results showed that female students were more willing to communicate and anxiety and perceived competence could strongly predict the frequency of WTC. The past decade has witnessed extensive studies into the direct and indirect impact of motivation on WTC (Baker \& MacIntyre, 2000; Hashimoto, 2002; Yashima, 2002). Concerning the role of WTC in EFL contexts, in 2007, Peng conducted a study on WTC and Chinese students' integrative motivation. He used Gardener's (1985) socio-educational model and 
McIntyre's (1998) WTC model and his findings showed that WTC significantly correlated with students' integrative motivation.

In another investigation, Yashima (2002) pointed to the direct association between WTC and attitude toward the international community in the EFL context. Further, students' linguistic self-confidence showed a positive relationship with WTC (Clément, Baker \& MacIntyre, 2003).

In China, Rong-lan (2012) investigated EI and foreign language learning and found that EFL students' EI, their learning strategies and English proficiency were significantly related to one another. According to MacIntyre and Charos (1996), an indirect connection exists between WTC and learners' personality.

Alemi (2012) studied Willingness to communicate in English among Iranian EFL engineering students and found that a more authentic language should be used to foster a more friendly relationship between teacher and learners and increase students' WTC.

In France, Croucher (2013) explored the extent to which religious beliefs and individualism/collectivism, related to communicative traits. Using WTC, SPCC and CA inventories to collect data, he found that CA was negatively associated with both WTC and SPCC. Further, high level of collectivism led to higher CA and lower WTC and SPCC.

\subsection{WTC, Communication Traits \& EI in Language Learning}

To date, many studies have been done on EI and WTC and communication traits separately and in relation with other variables, but the related studies into the association among EI, WTC and communication traits seems not bulky enough. After the formulation of multiple intelligence theory by Gardner (1983), the role of intelligences in learning a language has been the focus of many quests. The extant literature yields supportive evidence on constructive effect of multiple intelligence theory on language curriculum development (Kirkgoz, 2010) and language learning strategies (Akbari \& Hosseini, 2008).

Aki (2006) contended that being emotionally intelligent means being able to recognize, employ, comprehend and manage emotions and EI largely contributes to language learning.

Mohammadzadeh and Jafarigohar (2012) surveyed the relationship between multiple intelligence and WTC among 500 EFL students in Iran. The results of their study revealed a significant association among EFL students' multiple intelligences (especially interpersonal intelligence) and their WTC and this association was affected by students' gender. 
Tabatabaei and Jamshidifar (2013) found a significant relationship between Iranian EFL learners' EI and their WTC at university level. However, other communication traits (CA and SPCC) were not examined in that study. In the most recent inquiries, Gholami (2015) addressed the impact of EFL learners' EI on their WTC and the learners' gender differences. She found that WTC and EI were correlated with each other and female learners' WTC was higher than males' WTC. In another investigation about the EFL learners WTC and anxiety, Shahraki and Seyedrezaei (2015) indicated that EFL learners' anxiety was a hindrance to WTC.

\section{Objectives of the study and research questions}

According to Brackett and Mayer (2003), emotional intelligence functions as an instrument to empower a person to control emotions in stress-provoking circumstances. However, mixed results have been reported in terms of this status of the EI in educational settings (Barchard, 2003). Learners' WTC, as a determinant element in successful language-learning, could be affected by psychological variables (e.g. EI). In the latest study by Gholami (2015), the relationships among EFL learners' EI and WTC and gender differences were probed; however, there exists a paucity of supportive evidence in the review of related literature about the effect of EI on learners' WTC, SPCC and CA. Therefore, focusing on all aspects of learners' EI and their WTC, CA, and SPCC forms the core of the present study.

To put it more directly, the current quest seeks to answer the following research questions:

1. Are there any significant relationships among Iranian EFL students' emotional intelligence, and willingness to communicate, communication apprehension, and self-perceived competence at private language centers?

2. To what extent, if at all, can Iranian EFL students' emotional intelligence predict their willingness to communicate, self-perceived competence and communication apprehension?

\section{Methodology}

\subsection{Participants}

The participants of this study comprised 340 EFL students (200) females and 140 males ranging in age from 15 to 25) who were selected through cluster random sampling from private language centers in Yasuj, Iran. 


\subsection{Instruments}

\subsubsection{WTC questionnaire}

McCroskey and Richmond (1987) developed this scale to assess individuals' WTC. This questionnaire is composed of 20 items addressing individuals' tendency toward communication in different contexts. These items are in the form of statements to be ranked from zero=never to $100=$ always. The index of reliability was obtained through Cronbach Alpha for WTC inventory $(\alpha=.88)$.

\subsubsection{PRCA-24}

Personal Report of Communication Apprehension (PRCA-24) instrument (McCroskey, 1982) was utilized to measure participants' communication apprehension. Items of PRCA-24 evaluate communication apprehension in four contexts (public, meeting, group, and dyad) and with three types of receivers (friend, acquaintance, and stranger).This instrument are a 24-item self-report scale on five point likert format whereby 1 stands for strongly disagree and 5 stand for Strongly Agree. The level of Cronbach Alpha for PRCA was .85.

\subsubsection{SPCC scale}

Self-Perceived Communication Competence (SPCC) scale by McCroskey and McCroskey (1988) was used to measure the participants' perceptions about their communication competence. The participants were asked to rate their feeling on 12 statements from 1 to 100 . The index of reliability for SPCC was found to be acceptable $(\alpha=9)$.

\subsubsection{EQ-I}

To measure the participants' EI, Emotional quotient inventory (EQ-I) which was first developed in 1997 by Bar-On, was employed. EQ-I is a self-report scale including 133 items, which evaluate five broad subcomponents:

(a) Intrapersonal EQ (40 items), which is subdivided into emotional selfawareness ( 8 items), assertiveness (7 items), self-regard (9 items), selfactualization ( 9 items), and independence (7 items),

(b) Interpersonal EQ (29 items), which includes empathy (8 items), interpersonal relationship (11 items), and social responsibility (10 items),

(c) Adaptability EQ (26 items), which is divided into problem solving (8 items), reality testing (10 items), and flexibility ( 8 items).

(d) Stress management EQ (18 items), which is divided into stress tolerance (9 items) and impulse control (9 items). 
(e) The fifth is general mood EQ (17 items), which is divided into happiness (9 items) and optimism (8 items) (Bar-On, 1997, pp. 43-45). It should be noted that EQ-I is based on a five point Likert scale and the level of Cronbach alpha for this questionnaire was .91 .

\section{Procedure of the study}

Before administering the questionnaires, the researchers selected 13 private language centers out of 50 centers through cluster random sampling. Because, the private language centers were scattered in Yasuj, cluster random sampling was employed to select the participants of the study. Then the researchers negotiated with the principals of these centers to get the permission to distribute the questionnaires. All of the instruments were distributed simultaneously and in person. To avoid misunderstanding of the items in the questionnaires, Persian translation of WTC, SPCC, PRCA-24 and EQ-i were administered to the participants. To analyze the data, use was made of Statistical Package for Social Sciences (SPSS 18). Pearson correlations and multiple regression analyses were run to answer the research question.

\section{Result}

The results of Pearson correlation analyses showed that EFL student' EI dimensions were correlated with their WTC, SPCC, and CA. All five EI dimensions were found to be positively and significantly correlated with WTC (at $\mathrm{p}<0.01)$. However, according to Cohen (1988), if .10<r<.30, then the effect is small. Hence, the correlation between WTC and adaptability $\left(\mathrm{r}=0.195^{*}\right)$, and the correlation between general mood and SPCC ( $\mathrm{r}=0.298 * *)$ were not strong. The same positive and significant relationships exist among intrapersonal intelligence and SPCC $\left(\mathrm{r}=0.563^{* *}\right)$, interpersonal and SPCC $(\mathrm{r}=0.521 * *)$, stress management $\operatorname{SPCC}(\mathrm{r}=0.501 * *)$ and adaptability and SPCC $(\mathrm{r}=0.602 * *)$.

Table 2. Correlation analyses among EI variables, WTC, SPCC and CA.

\begin{tabular}{llll}
\hline EI variables & WTC & SPCC & CA \\
\hline Intrapersonal & $0.529^{* *}$ & $0.563^{* *}$ & $-0.391^{* *}$ \\
\hline Interpersonal & $0.599^{* *}$ & $0.521^{* *}$ & $-0.559^{* *}$ \\
\hline Stress management & $0.409^{* *}$ & $0.501^{* *}$ & $-0.459^{* *}$ \\
\hline Adaptability & $0.195^{* *}$ & $0.602^{* *}$ & $-0.499^{* *}$ \\
\hline General mood & $0.581^{* *}$ & $0.298^{* *}$ & $-0.409^{* *}$ \\
\hline
\end{tabular}

$* * \mathrm{p}<0.01$, total $\mathrm{N}=340$

On the contrary, the correlation among EI constructs and CA were all negatively significant. Among other things, the strongest correlation existed between SPCC and adaptability $(\mathrm{r}=0.602 * *)$, interpersonal and WTC $(\mathrm{r}=0.599 * *)$, interpersonal and $\mathrm{CA}\left(\mathrm{r}=-0.559^{* *}\right)$ respectively, and the smallest correlation was found between 
adaptability and WTC ( $\left.\mathrm{r}=0.195^{* *}\right)$, intrapersonal and CA $\left(\mathrm{r}=-0.391^{* *}\right)$ and SPCC and general $\operatorname{mood}\left(\mathrm{r}=0.098^{* *}\right)$, respectively. This implies that the higher levels of different subcomponents of emotional intelligence results in lower levels of communication apprehension.

To determine whether EFL students' EI could predict their WTC, SPCC and CA, multiple regression analyses were conducted via Enter method. In doing so, all EI variables were entered as independent or predictor variables and WTC, SPCC and CA were considered as dependent variables. Table 2 illustrates model summary in which more details were presented about the amount of variance, changes in dependent variables that could be explained by a mixture of predictor variables. In addition, the relative effect of each independent variable could be followed in the model summary.

Table 3. Multiple Regressions Analysis

\begin{tabular}{|c|c|c|c|c|c|c|}
\hline \multirow[b]{2}{*}{ EI variables } & \multicolumn{6}{|c|}{ Model Summary } \\
\hline & $\mathrm{R}$ & R Square & Adjusted $\mathrm{R}^{2}$ & $\begin{array}{l}\text { Std. Error of the } \\
\text { Estimate }\end{array}$ & $\mathrm{F}$ & sig \\
\hline Intrapersonal & 0.582 & 0.338 & 0.328 & 1.076 & 31.95 & 0.000 \\
\hline Interpersonal & 0.599 & 0.358 & 0.348 & 1.061 & 27.91 & 0.000 \\
\hline Stress management & 0.564 & 0.318 & 0.309 & 1.091 & 38.938 & 0.000 \\
\hline Adaptability & 0.621 & 0.385 & 0.372 & 1.042 & 25.895 & 0.000 \\
\hline General mood & 0.534 & 0.285 & 0.274 & 1.114 & 50.334 & 0.000 \\
\hline
\end{tabular}

According to the above table, $\mathrm{R}$ square demonstrates the amount of variance that could be explained by independent variables. As observed, intrapersonal variable could account for 33\%, interpersonal variable 35\%, stress management $31 \%$, adaptability $38 \%$ and general mood $28 \%$ variance in dependent variables (WTC, SPCC, and CA). General mood explained $28 \%$ amount of variance in dependent variables. Further, the regression analyses were significant (see the values of $\mathrm{F}$ and Sig in table 2).

Table 4. Beta, standardized beta \& significance level for the multiple linear regression analyses

\begin{tabular}{|c|c|c|c|c|c|c|c|c|c|c|c|c|}
\hline & & $\begin{array}{l}\text { WT } \\
\text { C }\end{array}$ & & & & SPCC & & & & CA & & \\
\hline & B & Beta & $\mathrm{t}$ & sig & B & Beta & $\mathrm{t}$ & sig & B & Beta & $\mathrm{t}$ & sig \\
\hline Intrapersonal & 0.23 & 0.21 & 3.49 & 0.000 & 0.002 & 0.002 & 0.03 & 0.000 & 0.97 & 0.92 & 1.46 & 0.000 \\
\hline Interpersonal & 0.139 & 0.13 & 2.56 & 0.000 & 0.24 & 0.23 & 3.89 & 0.000 & -0.3 & $-\bar{c}$ & -3.99 & 0.000 \\
\hline $\begin{array}{l}\text { Stress } \\
\text { management }\end{array}$ & 0.37 & 0.35 & 5.89 & 0.000 & 0.24 & 0.211 & 3.66 & 0.000 & -0.302 & $\overline{0}-31$ & -5.17 & 0.000 \\
\hline Adaptability & 0.23 & 0.23 & 3.75 & 0.000 & 0.33 & 0.001 & 2.31 & 0.000 & -0.24 & $\overline{0} .25$ & -4.3 & 0.000 \\
\hline General mood & 0.22 & 0.27 & 4.34 & 0.000 & 0.035 & .0203 & 0.93 & 0.000 & -0.25 & $\overline{0}-25$ & -4.03 & 0.000 \\
\hline
\end{tabular}


The results of regression analyses showed, as seen in table 3, that all the predictor variables (five subcomponents of EI) could significantly predict the dependent variables (WTC,CA and SPCC) $(\mathrm{p}<0.05)$.

\section{Discussion}

This study focused on finding the possible relationships among EFL learners`EI, WTC and communication traits (SPCC, CA) in the Iranian EFL context. Furthermore, the study aimed at examining whether and to what extent EFL students' EI could predict their WTC, SPCC and CA. The results showed that all EI subcomponents (intrapersonal, interpersonal, stress management, adaptability and general mood) had a significantly positive association with WTC. Gholami (2015) also found a positive relationship between EFL learners' WTC and their EI. One possible reason for this finding is that having a positive perception and an accurate understanding of one's emotions, which constitute intrapersonal subcomponent of EI, could encourage individuals to initiate talking. Krashen's (1981) affective filter hypothesis elucidated the role of positive emotions and lack of anxiety in motivating individuals to learn a language. Presumably, positive relationship among EFL students' EI dimensions with WTC could be related to affective filter hypothesis, as effective stress management, the ability of problem solving, feeling adaptable with new conversational contexts, and being flexible about adjusting feeling and thinking in new communicational situations are preconditions for WTC. Moreover, intrapersonal intelligence enables one to differentiate highly complex situations and feelings (Gardner, 1983). This finding is in congruence with findings of a study by Tabatabaei and Jamshidifar (2013) on the relationship between EFL students' EI and WTC The results of this study also indicated that interpersonal intelligence and WTC show stronger correlation than other EI variables. One justification for this result could be that understanding others and building a mutually satisfactory relationship with them could result in more WTC.

As McCroskey and Richmond (1982) elaborated on WTC, a person's readiness to communicate can occur in diverse contexts including interpersonal, small group, and public speaking contexts, and with strangers, acquaintances, and/or friends.

Moreover, the results revealed a positive association between SPCC and EI dimensions. McCroskey (1988) pointed that if a person has a positive and high SPCC then he believes in his abilities to do communication activities. Undoubtedly, a person with high level of SPCC could manage unfamiliar situations more easily (adaptability) and experience more happiness.

In an EFL classroom, students might be offered different conversational tasks that challenge their competence. Given that, EFL students with higher level of SPCC might be more successful problem solvers and tolerate stressful situations more effectively and consequently they feel better (general mood). 
The other result of this study was a significantly negative link between EI components and CA. Individuals with high CA might not be capable or confident enough to identify themselves in a social group and integrate with them (interpersonal intelligence). To put it more specifically, it might be fair to conclude that, higher CA emerged from lower EI. This finding is consistent with MacIntyre (1994) who found that CA negatively affects interpersonal interactions. This piece of finding is partially in congruence with Shahraki and Seyedrezaei (2015) who reported a negative correlation between anxiety and WTC in EFL learners.

The results of correlational analyses were in line with the findings of Mohammadzadeh and Jafarigohar (2012). They studied the impact of multiple intelligences (MI) on EFL students' WTC and found a significantly positive link between these variables especially between interpersonal, linguistic and intrapersonal intelligences.

As for the extent to which EFL students' EI could predict their WTC, SPCC and $\mathrm{CA}$, the results showed that all EI components were significant predictors of EFL students' WTC, SPCC and CA. The nature of learning a language might be different across diverse contexts. Due to the scant investigation available on the relationship among EI, WTC and communication traits, it might be difficult to explain this finding or compare it with recent studies. Clearly more WTC leads to more successful language learning (MacIntyre, 1998) and more WTC is bound to several personal, situational and psychological factors some of which were discussed earlier in this study.

To take all together, as MacIntyre (2003) argued, "to some extent language learning itself is prone to creating intense emotions" (p. 67). Thus, controlling negative feelings, feeling independent, managing stressful and unfamiliar situations, being aware of one's emotions and adjusting with new contexts, being more flexible to tolerate problems and pressures under communicational contexts all account for EI. As such, high EI could contribute to high WTC in EFL settings and consequently produce a more fruitful language learning experience.

\section{Conclusion}

To be equipped with a better comprehension of the nature of language learning, internal mechanism and interpersonal interaction plus social and intrapersonal engagements should be fully understood (Gardner, 1993). As stated previously, EI acts as an internal mechanism and external motivator for social interactions (Goleman, 2001). In line with the newly introduced importance of EI and WTC in language learning programs, this study attempted at investigating the possible relationships among EFL students' WTC,EI and communication traits. The results of this study suggested a significantly positive correlation among these variables. Further, it was indicated that EI subcomponents are strongly significant predictors 
of EFL students' WTC and SPCC and CA. Krashen (1981) argues findings that learning a language exposes most of the students to intense stress and pressure. As such, highly emotionally intelligent students could manage their negative feelings under cumbersome situations and effectively learn another language. Undeniably, learning a language necessitates starting a conversation and communication in L2; high WTC and overcoming SPCC and CA could assist EFL learners in language learning process. Overall, results of this study indicated that EFL students' tendency to initiate a communication and controlling anxiety and negative factors could be linked to EI.

Findings of this study could have some implications. For example, studying about the role of EI in learning a language might contribute to the deeper understanding of the process that students follow to learn a language and the abilities that they need to remove the preventive factors. Hence, findings of this study might offer more profound insights into the literature on the status of EI in learning a language. Additionally, because emotions can develop one's capability of thinking and planning to solve problems and orient people to their aims (Goleman, 1995), findings of the current study could raise teachers' consciousness about the role and significance of EI and emotional related traits in their teaching and learning a language and make them pay more decent attention to these aspects in teaching career. That is, EFL teachers might attempt at building an environment in which the focus is on enhancing students' EI and thereby maximize their WTC If they gain a more comprehensive understanding about hindrances and the impact of EI on motivating students to start a communication.

\section{References and notes:}

Akbari, R., \& Hosseini, K. (2008). Multiple intelligences and language learning strategies: Investigating possible relations. System, 36, 141-155.

Aki, Ö. (2006). Is emotional intelligence or mental intelligence more important in language learning? Journal of Applied Sciences, 6(1), 66-70.

Alemi, M. (2012). Willingness to communicate in English among Iranian EFL engineering students. TELL, 6, 1, 103-119.

Ahmadpour .Z and Khaasteh R.(2017) Writing Behaviors and Critical Thinking Styles: The Case of Blended Learning.Khazar Journal of Humanities and Social Sciences. 20,(1).Baku, Azerbaijan.5-25

Azimitabar, H., Gorjian, B., \& Pazhakh, A. (2012). The effect of emotional intelligence on male and female high school students' performance in production and recognition test item formats of reading comprehension. Advances in English Linguistics (AEL). 1 (1), 6166.

Baker, S. C., \& Macintyre, P. D. (2000). The role of gender and immersion in communication and second language orientations. Language Learning, 50 (2), 311- 341.

Bar-On, R. (1997). The emotional quotient inventory (EQ-i): A test of emotional intelligence. Toronto, Canada: Multi-Health Systems.

Bar-On, R. (2002). Bar-On Emotional Quotient Inventory: Short Technical Manual. Toronto, Canada: Multi-Health Systems 
Bar-On, R. (2006). The Bar-On model of emotional-social intelligence (ESI). Psicothema, (18), 1325.

Beatty, M. J., McCroskey, J. c., \& Heisel, A. D. (1998). Communication apprehension as temperamental expression: A communibiological paradigm. Communication Monographs, 65,197-219.

Besharat, M. (2005). The relationship between EQs and mental health. Unpublished MA Thesis, Allameh Tabataba'ii University, Tehran.

Brackett, M., \& Katulak, N. (2007). Emotional intelligence in the classroom. Skill-based training for teachers and students. In: Ciarrochi, Joseph/Mayer, John (eds.): Applying emotional intelligence. New York: 1-28.

Brackett M, Mayer JD. (2003). Convergent, discriminant, and incremental validity of competing measures of emotional intelligence. Personal. Soc. Psychol. Bull. 29, 1147-58.

Brown, D. (2000). Principles of Language Learning and Teaching (4th Ed.). New York: Pearson Education.

Salovey, P., \& Mayer, J. (1990). Emotional intelligence. Imagination, cognition, and personality, 9, 185-211.

Clément, R., Baker, S. C., \& MacIntyre, P. D. (2003). Willingness to communicate in a second language: The effects of context, norms, and vitality. Journal of Language and Social Psychology, 22 (2), 190-209.

Croucher, S. (2013). Communication Apprehension, Self-Perceived Communication Competence, and Willingness to Communicate: A French Analysis. Journal of International and Intercultural Communication, 6, 4, 298-316.

Gardner, H. (1983). Frames of mind. New York: Basic Books.

Gardner, R. C. (1985). Social psychology and second language learning: The role of attitude and motivation. London: Edward Arnold.

Gholami, L. (2015). Willingness to Communicate and its Relationship with Emotional Intelligence and Gender Differences, International Letters of Social and Humanistic Sciences, 52, 87-94

Goleman, D. (1995). Emotional intelligence. New York: Bantam.

Goleman, D. (2001). Emotional intelligence: Issues in paradigm building. In C. Cherniss \& D. Goleman (Eds.), The emotionally intelligent workplace (pp. 13-26). San Francisco: Jossey-Bass

Hashimoto, T. (2002). The constructive approach to the dynamical view of language. In Angelo Cangelosi and Domenico Parisi, (Ed.), Simulating the Evolution of Language 307-324. London: Springer Verlag.

Krashen, S. (1981). Second language acquisition and second language learning. Oxford: Pergamum Press.

Kirgoz, Y. (2010). Catering for multiple intelligences in locally published textbooks in Turkey. Procedia social and Behavioral Sciences, 3, 127-130.

Lenka, S. K., \& Kant, R. (2012). Emotional intelligence of secondary school teachers in relation to their professional development. Asian Journal of Management Sciences and Education, 1(1), 90-101.

Mayer, J., Caruso, D., \& Salovey, P. (1999): "Emotional intelligence meets traditional standards for intelligence". Intelligence 27, 267-298.

MacIntyre, P. D. (1994). Variables underlying willingness to communicate: A causal analysis. Communication Research Reports, 11(2), 135-142.

MacIntyre, P. D. (1998). Language anxiety: A review of the research for language teachers. In D. J. Young (Ed.), Affect in foreign language and second language learning (pp. 24-45). Boston: McGraw-Hill.

MacIntyre, P.D., Charos, C. (1996). Personality, attitudes, and affect as predictors of second language communication. Journal of Language and Social Psychology, 15 (1), 3-26

MacIntyre, P. D., Clement, R., Dornyei, Z., \& Noels, K. (1998). Conceptualizing Willingness to Communicate in a L2: a Situational model of L2 Confidence and Affiliation. The modern Language Journal, 82, 545-562. 
MacIntyre, P. D. (2003). Willingness to Communicate in the Second Language: Proximal and Distal Influences. Paper presented at the 33rd annual conference of the Canadian association of Applied Linguistics, Halifax, NS, Canada.

McCroskey, J. C. (1992). Reliability and Validity of the Willingness to Communicate scale. Communication Quarterly, 40 (1), 16-25.

McCroskey, J. C. (1997). Willingness to Communicate, Communication Apprehension, and SelfPerceived Communication Competence: Conceptualizations and Perspectives. In Daly, et al. Avoiding communication: Shyness, Reticence, \& Communication Apprehension, (pp.75-108). Cresskill, NJ: Hampton Press.

McCroskey, J. C. (1982). An Introduction to Rhetorical Communication (4th Ed). Englewood Cliffs, NJ: Prentice- Hall.

McCroskey, J. C., \& McCroskey, L. L. (1988). Self-report as an approach to measuring communication competence. Communication Research Reports, 5, 108-113.

McCroskey, j. c., \& Richmond, V. P. (1982).Communication apprehension and shyness: Conceptual and operational distinctions. Central States Speech Journal, 33, 458-468.

McCroskey, J. C., \& Richmond, V. P. (1987). Willingness to communicate. In J. C. McCroskey, \& J. A. Daly (Eds.), Personality and interpersonal communication (pp. 129 156). Newbury Park, CA: SAGE Publications.

McCroskey, J. C., \& Richmond, V. P. (1990). Willingness to communicate: Differing cultural perspectives. Southern Communication Journal, 56, 72-77.

McCroskey, J. C., \& Richmond, V. P. (1991). Willingness to communicate: A cognitive view. In M. Booth-Butterfield (Ed.), Communication, cognition, and anxiety (pp.19-37). Newbury Park, CA: Sage.

Mohammadzadeh, A., \& Jafarigohar, M. (2012). The relationship between willingness to communicate and multiple intelligences among learners of English as a foreign language, English Language Teaching, 5, 25-32.

Pishghadam, R. (2007). On the influence of emotional and verbal intelligence on second language learning. Unpublished doctoral dissertation, AllamehTabataba'ii University, Tehran, Iran.

Pishghadam, R. (2009). Emotional and verbal intelligences in language learning. Iranian Journal of language Studies, 3, 43-64.

Richmond, V.P. (1991). Communication in the classroom: Power and motivation. Communication Education, 39, 181-195.

Roach, K, D. (1999). The influence of teaching assistant willingness to communicate and communication anxiety in the classroom. Communication Quarterly, 47, 2, 120-144.

Rokhi, S., Hamidi, H., \& Gorgani, T. (2014). Investigating relationship between emotional intelligence and language achievement: a case study of TEFL and non-TEFL students. International journal of language learning and applied linguistics world, 5 (3), 117-127.

Rong, I. (2012). The Role of EQ in EFL Students' Foreign Language Learning. Sino-US English Teaching, 9 (11), 1676-1694.

Salami, S. O. (2007). Emotional Intelligence and self-efficacy to work attitudes among secondary school teachers in southwestern Nigeria. Essays in Education, 20, 43-56.

Salovey, P., \& Mayer, J. (1990). Emotional intelligence. Imagination, cognition, and personality, 9 , $185-211$.

Sharaki, N., \& Seyedrezaei, H.(2015). The Relationship between EFL Learners' Language Anxiety and their Willingness to Communicate. Journal of Language Sciences \& Linguistics, 3 (5), 96-101.

Tabatabaei, O., \& Jamshidifar, M. (2013). The relationship between Emotional Intelligence and Willingness to Communicate among EFL Learners. International Journal of English Language Education, 2 (1), 90-100.

Yashima, T. (2002) Willingness to communicate in a second language: The Japanese EFL context. Modern Language Journal, 86, 54-66. 


\title{
Summary
}

\section{On the Relationships among EFL Learners' Willingness to Communicate, Communication Apprehension, Self-Perceived Competence and Emotional Intelligence}

\author{
Saeed Mehrpoor \\ Shiraz University, Iran \\ Neda Soleimani \\ Shiraz University, Iran
}

This study focused on the relationships among language learners' communication-related variables including willingness to start a communication (WTC), self-perceived communication competence (SPCC), communication apprehension (CA) and different subcomponents of emotional intelligence (EI). To this end a battery of questionnaires (WTC $=20$ items, Personal Report of Communication Apprehension (PRCA=24), SelfPerceived Communication Competence (SPCC =12), Emotional quotient inventory (EQI=133)) were distributed among 340 randomly selected Iranian EFL learners in Yasuj, Iran. Correlation and regression analyses showed that EFL student' EI dimensions were correlated with their WTC, SPCC, and CA. All five EI dimensions were found to be positively and significantly correlated with WTC (at p<0.01). On the contrary, the correlation among EI constructs and CA were all negatively significant. Moreover, EFL learners' EI dimensions could significantly predict their WTC and other communication related variables. Findings of the study would have implications for both practicing and prospective teachers.

Keywords: Willingness to communicate, communication apprehension, self-perceived apprehension, emotional intelligence, EFL learners 